\title{
Comment
}

\section{Discussões sobre a Teoria vygotskyana para o Ensino Médio}

\author{
Maria Deuzani da Silva ${ }^{1}$; Eliete Lira Nobre Ferreira ${ }^{2}$
}

\begin{abstract}
Resumo: A adolescência é uma fase que predomina o desenvolvimento de inúmeras habilidades cognitivas, sociais e afetivas. Pensar no ensino para essa categoria é ir além dos processos didáticos característicos das fases anteriores. Uma teoria psicológica que atende a essas necessidades é a sócio-construtivista de Vygotsky a partir das relações entre linguagem, cultura e níveis ou zonas de desenvolvimento. A necessidade docente de compreender a contribuição dessa teoria para o processo educativo no ensino médio explica esse estudo. Nesse sentido, objetivou-se discutir a docência no ensino médio considerando a teoria vygotskyana. Como objetivos específicos foram ressaltados: relacionar a teoria vygotskyana com a educação no ensino médio e refletir sobre a docência/mediação nessa etapa da Educação Básica. Pesquisa bibliográfica de abordagem qualitativa, cujo método de análise dos dados foi o indutivo. Os resultados demonstraram que cada etapa da Educação Básica possui particularidades, principalmente considerando as faixas etárias dos alunos, que é uma característica que justifica sua existência. Portanto, cabe aos professores compreenderem isso para que suas atuações sejam as mais eficientes possíveis. O docente tem a capacidade, não só de ensinar, mas de fazer com que o potencial de desenvolvimento dos seus alunos seja explorado da melhor maneira possível. Com isso, ele carrega a responsabilidade pela eficiência na aplicação da teoria vygotskyana e da didática. Além da responsabilidade em garantir uma educação de qualidade.
\end{abstract}

Palavras-chave: Zonas de desenvolvimento; Potencial do aluno; Didática.

\section{Discussions on the Vygotsky's Theory for High School}

\begin{abstract}
Adolescence is a stage that dominates the development of many cognitive, social and affective skills. Thinking about education for this category is to go beyond the typical learning processes of the previous phases. A psychological theory that meets these needs is the social constructivist Vygotsky from the relationships between language, culture and levels or development zones. The teachers need to understand the contribution of this theory to the educational process in high school explains this study. In this sense, it aimed to discuss teaching in high school considering Vygotsky's theory. Specific objectives were highlighted: Vygotsky's theory relate to education in high school and reflect on the teaching / mediation in the Basic Education stage. Bibliographical research of qualitative approachwhich method of data analysis was inductive. The results showed that each stage of basic education has particularities, especially considering the age of the students, which is a feature that justifies its existence. So it is up to the teachers to understand this so that their actions are as efficient as possible. The teacher has the ability not only to teach but to make the development potential of their students is exploited in the best possible way. With that, he bears responsibility for the efficient application of Vygotsky's theory and didactics. Besides the responsibility to ensure quality education.
\end{abstract}

Keywords: Development zones; Potential of the student; Didactics.

\footnotetext{
${ }^{1}$ Mestranda em Ciências da Educação pela Universidade Anne Sullyvan. Graduada em Letras pela Universidade Vale do Acaraú (UVA) e em Pedagogia e Biologia pela Universidade Regional do Cariri (URCA); Especialista em Gestão Escolar pela Faculdade de Juazeiro do Norte (FJN) e Mestranda em Ciências da Educação pela Anne Sullivan University. Contato: deuzanir30@ hotmail.com.

${ }^{2}$ Professora da Secretaria de Educação do Estado do Ceará.
} 
Id on Line Revista Multidisciplinar e de Psicoloqia

Id on Line Multidisciplinary Journal and Psycology

\section{Introdução}

A educação acontece por duas vias, uma formal e outra informal. Ambas, possuem características comuns destacando-se a mediação que acontece entre um 'aprendiz' e um 'mestre' ou objeto. No meio informal, a criança pode aprender com seus pais, com outras crianças e/ou com experiências vividas, caracterizando assuntos diversos. No formal, pode ser com o professor e/ou com o livro, objetivando a aprendizagem de um conhecimento científico. A mediação entre as experiências e a nova informação leva o indivíduo a um novo conhecimento.

Nessa ideia sustenta-se a teoria de Vygotsky (1896-1934), sócio-construtivista, de Zona de Desenvolvimento Iminente - ZDI, que é a mediação entre o Nível de Desenvolvimento Real - NDR e o Potencial. Segundo essa teoria, a partir da mediação o indivíduo aprenderá um novo conhecimento e assim atingirá um maior desenvolvimento (REGO, 2002).

$\mathrm{Na}$ teoria supracitada sustentam-se diversas outras teorias pedagógicas que se apoiam na premissa de que as influências das relações sociais - do ensino - agem no desenvolvimento e na aprendizagem do indivíduo que possui um potencial a ser explorado e que carrega experiências e conhecimento.

A didática utiliza-se dessas ideias porque sua função é gerar meios para que a aprendizagem aconteça (LIBÂNEO, 2011). Portanto, algumas tendências pedagógicas foram influenciadas, bem como alguns professores que também atuam nessa cadeia de influencias. Em uma cadeia de eventos, essa teoria fornece informações de como a aprendizagem acontece, a didática gera meios que facilitem sua aplicação e o docente realiza a mediação necessária.

A educação desenvolve-se nesse emaranhado de relações que objetivam um desenvolvimento integral do indivíduo por meio da aprendizagem de diversos conhecimentos fundamentais.

A justificativa desse estudo está na importância de compreender a contribuição da teoria de Vygotsky (REGO, 2002) para educação e o ensino na última etapa da Educação Básica.

O objetivo geral desse trabalho é discutir a docência no ensino médio considerando a teoria vygotskyana. Os específicos são: relacionar a teoria vygotskyana com a educação no ensino médio e refletir sobre a docência/mediação nessa etapa da Educação Básica. 
Id on Line Revista Multidisciplinar e de Psicoloqia

Id on Line Multidisciplinary Journal and Psycology

Trata-se de uma pesquisa bibliográfica de abordagem qualitativa, pois com base em leituras de artigos e livros, busca-se apresentar reflexões sobre o tema.

O método adotado é o indutivo que se caracteriza como um processo mental utilizado para chegar a objetivo proposto, partindo de fatos particulares, comprovados para uma conclusão genérica, científica (SERVO, BERVIAN e DA SILVA, 2007).

\section{Teoria vygotskyana para o Ensino Médio}

A etapa final da Educação Básica tem o papel de tornar o aluno apto a interagir nos diversos contextos sociais de modo que tenha autonomia para dar prosseguimento aos estudos e/ou profissão. Nessa etapa, ocorre "consolidação e aprofundamento dos conhecimentos adquiridos no ensino fundamental" (BRASIL, p. 28, 2010).

Para que isso ocorra, é necessário considerar que o aluno carrega certa quantidade de conhecimentos que precisam ser explorados para que se tornem firmes, em outras palavras, o aluno precisa dominá-los. Além de aprendê-los deve saber aplicá-los. Complementando essa ideia, deve haver aprofundamento desses conhecimentos no sentido de explorar sua complexidade para que o aluno amplie sua compreensão sobre eles.

É nesse ponto que a teoria de Vygotsky (1988) pode ser aplicada, pois considerando o nível de desenvolvimento real do aluno, adquirido nas etapas anteriores; e, explorando seu potencial por meio de objetivos preestabelecidos e possíveis de serem alcançados, a mediação leva o aluno a uma nova aprendizagem e a um nível mais elevado de desenvolvimento.

Essa mediação é eficiente porque considera, não só a teoria vygotskyana, mas a didática que organiza o ensino com base no contexto sociocultural, no desenvolvimento do ser humano e na complexidade do conhecimento que é distribuído nos vários anos das etapas da Educação Básica.

A didática, enquanto ciência pedagógica, desenvolve métodos para facilitar e garantir a aprendizagem, bem como objetivos capazes de explorar o potencial dos alunos de cada ano escolar (LIBÂNEO, 2011). E no ensino médio compreende que os alunos possuem capacidade para desenvolver o pensamento autônomo e crítico sobre diversos conhecimentos. 
Essa autonomia e criticidade estão estreitamente arroladas às relações sociais, pois ao considerar que a escola forme o aluno também para o exercício da cidadania, esse deva ser consciente com relação ao papel social e à participação ativa quanto aos direitos e deveres legais e morais. O pensamento crítico, além de contribuir para com o dever cívico, permite ao indivíduo emitir juízo sobre várias questões sociais e sobre vários conhecimentos de modo geral. Assim, permite aumentar as possibilidades nas relações sociais.

Essa ideia social e construtivista foi corroborada por Vygotsky (1988) quando afirma que o ser humano desenvolve-se por meio dessas relações e o pensamento crítico potencializa o desenvolvimento humano.

A prática pedagógica diária dos professores também contribui para com a Pedagogia de modo que o professor, não só aplique a didática como a amplie/complemente e a adapte às necessidades com que se depara (LIBÂNEO, 2011). No final, a arte de aplicar todas essas teorias - o ensino - é que determina a eficiência delas no contexto escolar para promoção da aprendizagem e do desenvolvimento dos alunos.

Uma vez considerado o ensino como tarefa do professor, a mediação pode ser menos ou mais eficiente a depender de vários aspectos educacionais, mas principalmente da habilidade docente em realizar uma leitura do ambiente e adequá-lo às necessidades reais do aluno e às circunstâncias que são características de cada disciplina.

A zona de desenvolvimento iminente, em teoria, leva esse indivíduo a um novo estado de desenvolvimento e de aprendizagem. Entretanto, o professor deve conhecê-la bem para que a utilize com eficiência juntamente com as ferramentas didáticas aplicáveis disponíveis. Desse modo, garantirá uma mediação capaz de explorar melhor o potencial dos alunos.

Vários autores consideram a importância e o papel das relações sociais na formação humana, pois entendem que "as funções psicológicas emergem no plano das relações sociais, e o indivíduo se constrói a partir delas" (GOÉS, 2000, p. 121). Esses autores partem da teoria sócio-construtivista em que a aprendizagem e o desenvolvimento sejam produtos da interação social.

Para Vygotsky (1988), a aprendizagem determina o processo de desenvolvimento aprendendo e desenvolvendo por meio da linguagem e interação com a cultura e com outros indivíduos. Mas, se a aprendizagem determina o desenvolvimento, que aprendizagem é necessária para garantir o pleno desenvolvimento do educando? 
Nesse sentido, se a escola é responsável por garantir o pleno desenvolvimento do educando ela também é responsável por garantir a plena aprendizagem? E o que seria essa plena aprendizagem?

Segundo o minidicionário Rocha (2001), plena traz sentido de totalidade que por sua vez possui o sentido de completo. Obviamente a escola não tem possibilidade de ensinar todos os conhecimentos existentes, assim como os seres humanos não possuem a capacidade para aprendê-los. Mas, esse sentido de pleno refere-se à parte essencial dos conhecimentos dispostos nas principais ciências aplicadas nas disciplinas escolares. $\mathrm{O}$ pleno estaria relacionado com a ideia de geral, de modo a fazer referência aos diversos conhecimentos fundamentais. No entanto, o que fica claro é que o termo não é o mais apropriado.

Em outro ponto de vista, se o pleno desenvolvimento do educando faz referência ao intelectual, físico e espiritual (SHERAFAT, s/p. 200-?), a aprendizagem plena também deverá relacionar-se a isso. Até aqui nenhuma novidade! Contudo, as escolas priorizam o desenvolvimento intelectual e não haveria problema quanto a isso se os outros dois aspectos do pleno desenvolvimento ganhassem mais atenção nos currículos escolares.

Enfim, pode-se traçar uma relação de dependência das várias influências para o desenvolvimento e a aprendizagem do aluno, como a teoria vygotskyana, a didática, além de o professor que possui a tarefa de aplicá-las - teoria (s) e ciência pedagógica - e é o principal responsável pela mediação entre o nível de desenvolvimento real e o potencial do aluno.

\section{Teoria vygotskyana e a docência}

O professor do ensino médio depara-se com alunos adolescentes que possuem uma considerável bagagem de conhecimentos. Eles conseguem enxergar e fazer relações concretas e abstratas, além de possuírem capacidade crítico-reflexiva sobre alguns temas. Isso mostra que possuem um pensamento mais complexo se comparados com alunos de séries anteriores. Logo são estudantes diferentes e com necessidades educativas diferentes (RELVAS, 2012).

Diante dessa ponderação, o que justificaria a atuação do professor ser exatamente igual? Os mesmos métodos e estratégias, objetivos similares aos anteriores que não exploram 
Id on Line Revista Multidisciplinar e de Psicoloqia

Id on Line Multidisciplinary Journal and Psycology

profundamente a complexidade do pensamento dos alunos, conteúdos tratados sob as mesmas perspectivas, etc.

A zona de conforto ${ }^{1}$ pode até ser segura, porém limitada. A atividade de mediação para o Ensino Médio deve considerar as necessidades desses alunos. A teoria vygotskyana sobre a ZDI tem esse mesmo princípio, mas as ferramentas didáticas de aplicação não podem ser apenas as mesmas, pois necessidades educativas diferentes necessitam de ferramentas didáticas diferentes, capazes de melhorar o aproveitamento do potencial dos alunos.

Relação, reflexão, pensamento crítico e autonomia de pensamento devem ser explorados. E a aprendizagem deve ocorrer por meio dessa capacidade de pensamento e não apenas pela decodificação, interpretação e memorização, pois do contrário, o nível de desenvolvimento real não estaria sendo considerado de fato.

Logo, o potencial também não estaria sendo explorado de maneira eficiente. Isso implica em elaboração de objetivos, estratégias e métodos mais complexos ou que aproveitem melhor a complexidade de pensamento e o potencial dos alunos adolescentes.

A tarefa do professor não é simples e nem tão fácil quanto parece. Exige muitas qualidades como a dedicação, pois, o rendimento dos alunos pode depender em parte disso. E quando se trata de potencial toda parte a mais que possa ser explorada/atingida é importante. Afinal, ensinar qualquer um pode, mas ser professor não é privilégio de qualquer um.

\section{Considerações Finais}

A mediação se estabelece entre um aprendiz e um mestre e é a base para que a aprendizagem aconteça, seja ela, formal ou informal. A Psicologia tratou dessa mediação de diferentes formas, mas a teoria sócio-construtivista de Vygotsky chama a atenção ainda hoje pela sua relação com a contemporaneidade.

Para a Psicologia, a Zona de Desenvolvimento Iminente - ZDI é essa mediação que deve olhar para um presente chamado Nível de Desenvolvimento Real - ZDR e um futuro chamado Zona de Desenvolvimento Potencial - ZDP. Para a didática, esses três aspectos podem

\footnotetext{
${ }^{1}$ Zona de conforto é uma região onde o homem não se sente ameaçado e por isso, permanece com os mesmos pensamentos e comportamentos diante das situações de vida (SIGNIFICADOS, 2011).
} 
Id on Line Revista Multidisciplinar e de Psicoloqia

Id on Line Multidisciplinary Journal and Psycology

ser adaptados, considerando os conteúdos de ensino, as particularidades do processo de ensino e de aprendizagem e as habilidades dos estudantes.

Quando se pensa em adolescentes, essa teoria parece fazer mais sentido ainda, pois cada etapa da Educação Básica possui particularidades, principalmente considerando as faixas etárias dos alunos, que é uma característica que justifica sua existência. Portanto, cabe aos professores compreenderem isso para que suas atuações sejam as mais eficientes possíveis.

Contudo, o professor precisa compreender não só essa teoria, mas também as demais que possam promover/possibilitar/contribuir para com isso, de modo que possa facilitar suas aplicações por meio do domínio da didática.

O professor como mediador tem a capacidade, não só de ensinar, mas de fazer com que o potencial de desenvolvimento dos seus alunos seja explorado da melhor maneira possível. Com isso, ele carrega a responsabilidade pela eficiência na aplicação da teoria vygotskyana e da didática. Além da responsabilidade em garantir uma educação de qualidade.

\section{Referências}

BRASIL. Ministério da Educação. Lei de Diretrizes e Bases da Educação Nacional, lei n ${ }^{\circ}$ 9.394/96. Brasília, 2010. Disponível em: <http://www.planalto.gov.br/ccivil_03/leis/L9394.htm>. Acesso em: 27 jun 2016.

GÓES, Maria Cecília Rafael de. A formação do indivíduo nas relações sociais: Contribuições teóricas de Lev Vigotski e Pierre Janet. In: Educação \& Sociedade, ano XXI, n 71 , Julho/00. Disponível em: <http://www.scielo.br/pdf/es/v21n71/a05v2171.pdf>. Acesso em: 25 de jul. de 2016.

LIBÂNEO, José Carlos. Didática e trabalho docente: a mediação didática do professor nas aulas. In: Concepções e práticas de ensino num mundo em mudança. Diferentes olhares para a didática. Goiânia: PUC GO, p. 85-100, 2011.

REGO, Teresa Cristina. Vygotsky: uma perspectiva Histórico-Cultural da Educação. Rio de Janeiro: Vozes, 2002.

RELVAS, Marta Pires. Neurociência na Prática Pedagógica. Wak Editora: Rio de Janeiro, 2012. 
ROCHA, Ruth. Minidicionário: enciclopédico escolar. 10 ed. $5^{\text {a }}$ impressão. Scipione: São Paulo, 2001.

SHERAFAT, Felora Daliri. Desenvolvimento Pleno. In: Trabalho e o Reencontro de Interesses, Editora Núr, Rio do Janeiro, 2004. Revisado por Editor do Webartigos.com. Disponível em: http://www.webartigos.com/artigos/desenvolvimento-pleno/10220/. Acesso em: 27/07/2016.

SIGNIFICADOS. O que é Zona de Conforto. Publicado em 2011. Disponível em: <http://www.significados.com.br/zona-de-conforto/>. Acesso em: 29 jul 2016.

VYGOTSKY, Lev Semenovich. Aprendizagem e desenvolvimento intelectual na idade escolar. In: Linguagem, desenvolvimento e aprendizagem. São Paulo: Ícone EDUSP, 1988.

\section{Como citar este artigo (Formato ABNT):}

SILVA, M.D.; FERREIRA, E.L.N. Discussões sobre a Teoria Vygotskyana para o Ensino Médio. Id on Line Revista Multidisciplinar e de Psicologia, Outubro de 2016, vol.10, n.31, p. 170-177. ISSN 1981-1179.

Recebido: $15 / 08 / 2016$.

Aceito: $17 / 08 / 2016$ 